\title{
Proximal Arteriovenous Fistulas in Hemodialysis Patients: Advantages and Disadvantages
}

Cengiz Güven ${ }^{1}$, Öznur Uludağ ${ }^{2}$

1. Cardiac/Thoracic/Vascular Surgery, Adıyaman University Faculty of Medicine, Adıyaman, TUR 2. Anesthesiology and Reanimation, Adıyaman University Faculty of Medicine, Adıyaman, TUR

Corresponding author: Cengiz Güven, guvencengz@yahoo.com

\begin{abstract}
Introduction: The main objective of the present study is to investigate the advantages and disadvantages of proximal arteriovenous native fistulas. Hemodialysis is indispensable for patients with end-stage renal disease. For this purpose, arteriovenous fistulas (AVFs) are used. Among the native fistulas, distal radiocephalic AVF is the most preferred. However, brachiocephalic AVF (BCAVF) and brachiobasilic AVF with basilic vein transposition (basilic vein transposition arteriovenous fistula [BVTAVF]) can be used for a long time in dialysis patients whose distal vascular bed is depleted.
\end{abstract}

Methods: This is a retrospective study of 117 AVFs (BCAVF and BVTAVF), in patients with end-stage chronic renal disease, that were opened with a surgical technique (2012-2018). The postoperative two-year patency rates, AVF locations, complications, and the advantages and disadvantages of these fistulas are reviewed and recorded in the light of the literature.

Results: The mean age of the patients ( 52 men and 65 women) was $60.6 \pm 13.6$ years. The percentages of primary patency rates at $3,6,9,12$, and 24 months were $96.6 \%, 93.1 \%, 92 \%, 87.4 \%$, and $82.8 \%$ in BCAVF patients, and $96.7 \%, 93.3 \%, 90 \%, 86.7 \%$, and $80 \%$ in BVTAVF patients, respectively. The percentages of secondary patency rates at 6,12 , and 24 months were $100 \%, 93.3 \%$, and $86.7 \%$ in BCAVF patients, and $100 \%$, $100 \%$ and $87.7 \%$ in BVTAVF patients, respectively. Fistula thrombosis was seen as the most common complication. The early complication was bleeding/hematoma. As late complications, we encountered steal syndrome, ischemic pain in the relevant extremity, pseudoaneurysm, and high-output heart failure.

Conclusion: Proximal AVFs are preferable fistulas with early maturation and high primary patency rates. We believe that relatively high complications can be avoided by opening fistulas with an appropriate surgical technique.

Review began 10/22/2020 Review ended 11/08/2020 Published 11/23/2020

\section{(c) Copyright 2020}

Güven et al. This is an open access article distributed under the terms of the Creative Commons Attribution License CC-BY 4.0., which permits unrestricted use, distribution, and reproduction in any medium, provided the original author and source are credited.
Categories: Cardiac/Thoracic/Vascular Surgery, Nephrology

Keywords: hemodialysis, complication, brachiocephalic fistula, basilic vein transposition

\section{Introduction}

Hemodialysis patients with central venous catheters have larger mortality due to infections. But the hemodialysis patients with native arteriovenous fistulas (AVFs) have a long period of patency and less complications. Therefore, for patients whose life is dependent on hemodialysis, AVFs are the most preferred renal replacement methods. A distal radiocephalic AVF is the frequently preferred vascular access technique among fistulas [1]. Proximal fistulas opened using the brachial artery as the artery and the cephalic and basilic vein as the vein are alternative vascular access routes in patients with an insufficient or depleted distal vascular bed [2]. Brachiocephalic AVF (BCAVF) and brachiobasilic AVF with basilic vein transposition (basilic vein transposition arteriovenous fistula [BVTAVF]) can be used for a long time with their excellent potency ratio [3]. These fistulas have some disadvantages and advantages. Beside the advantages such as early maturation and earlier dialysis start, BCAVF has disadvantages such as steal syndrome, venous hypertension, and edema in the arm, and BVTAVF has disadvantages such as bleeding, hematoma, aneurysm formation, and steal syndrome [4-6].

The main objective of this study is to examine patients with proximal AVFs and share AVFs' advantages and disadvantages in the light of the literature.

\section{Materials And Methods}

This study was carried out in the Adiyaman University Medical Faculty Cardiovascular Surgery Clinic, Adıyaman, Turkey. A total of 117 patients with proximal AVF opening were admitted. All patients with autologous proximal AVF and over the age of 18 between June 2012 and December 2018 were included in the study. Patients with distal AVFs and AVFs opened with synthetic graft were not included in the study. This was a retrospective cohort study and the data collected were used for study purposes only. This study was approved by the Institutional Review Board of the Adıyaman University Medical Faculty, where the study 


\section{Cureus}

was conducted (approval no. 2020/1-5). All surgical procedures are recorded in our database. The patients who had proximal AVF operated in our clinic between June 2012 and December 2018 were evaluated in terms of fistula location, dialysis initiation times, complications, advantages and disadvantages, and primary and secondary patency rates. The access was considered mature and successful with a flow rate of at least 350 $\mathrm{mL} / \mathrm{min}$ at the control with colored venous Doppler ultrasonography and it was recorded as the first dialysis time in the postoperative one- and two-month follow-ups of the patients.

\section{Statistical analyses}

Statistical analysis to determine patency rates was performed by Kaplan-Meier method using the GraphPad Prism 8.0.2 (GraphPad Software, Inc., CA; retrieved from http://www.graphpad.com/scientificsoftware/prism/). An independent two-sample t-test was used to compare the first cannulation time. This result was reported as mean $\pm \mathrm{SD}$. Categorical variables were compared using the chi-square homogeneity test and chi-square independence test. Data were expressed as counts and percentages. A p value $<0.05$ was considered statistically significant.

\section{Surgical technique}

BCAVF patients were operated under local anesthesia, while BVTAVF patients were operated with an axillary block. Blood pressure, pulse, and pulse oximetry monitoring was performed in all patients. In BCAVF, following appropriate staining and covering, an appropriate incision (approximately $3.5-4 \mathrm{~cm}$ ) was made in the antecubital region of the relevant extremity. The cephalic vein and brachial artery were found and turned. After the cephalic vein was released, its distal part was tied and cut. Lumen was washed with heparinized fluid. Systemic 5000 IU heparin was administered to the brachial artery. Vascular clamps were placed five minutes later. Approximately a $3.5-4 \mathrm{~mm}$ arteriotomy was performed. The cephalic vein was anastomosed to the brachial artery using an end-to-side anastomosis technique (Figure 1).

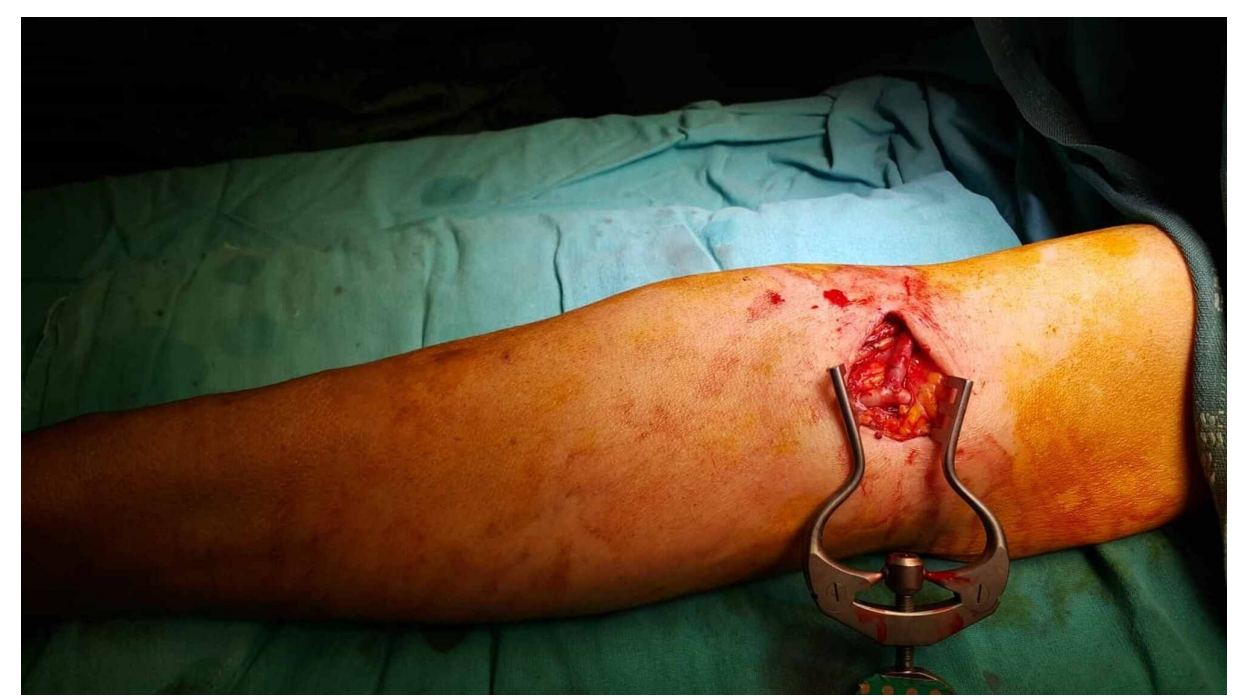

FIGURE 1: Brachiocephalic arteriovenous fistula

Then, the subcutaneous tissue and skin were closed with appropriate sutures.

Following appropriate staining and covering, an appropriate skin incision was made from the antecubital area of the relevant extremity in BVTAVF. The basilic vein was found, turned, and explored in the axillary region until it was poured into the axillary vein. The lateral branches were tied and released (Figure 2). 


\section{Cureus}

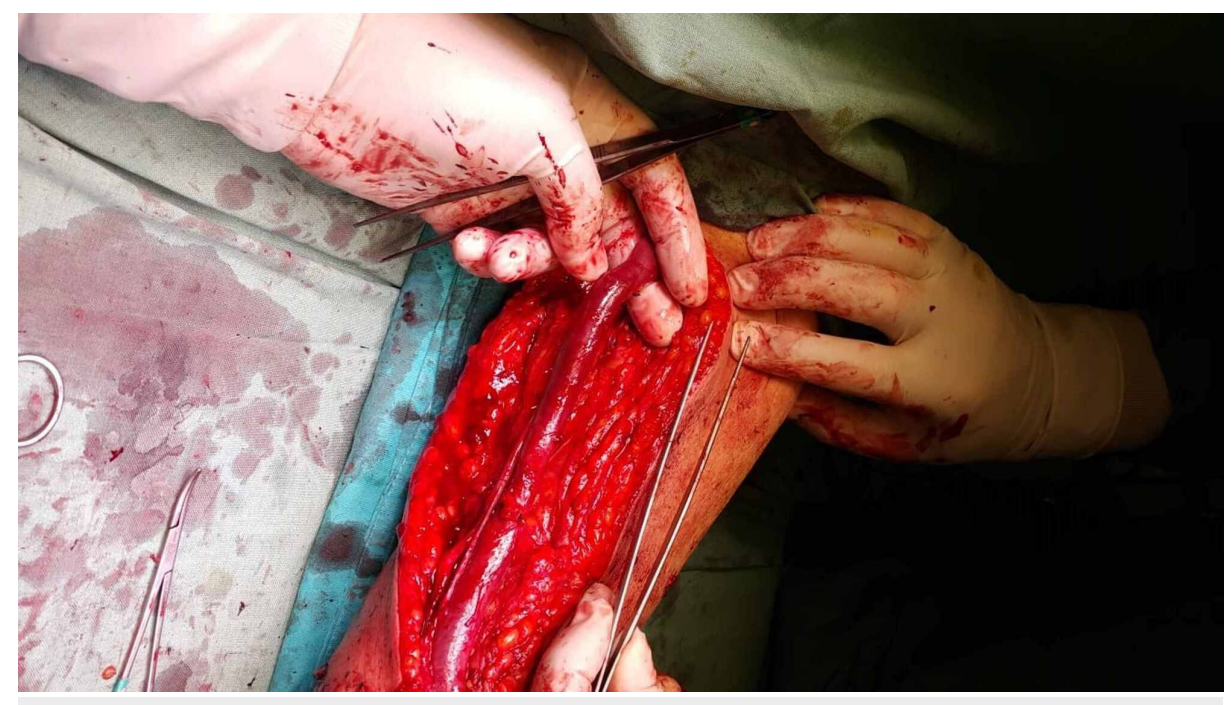

FIGURE 2: Basilic vein transposition arteriovenous fistula

Lumen was washed with heparinized fluid. The brachial artery was found and turned. The basilic vein was passed through a subcutaneous tunnel in the lateral region. After $5000 \mathrm{IU}$ systemic heparin was given, vascular clamps were placed in the brachial artery. A 3.5-4 mm arteriotomy was performed on the brachial artery. The basilic vein passed through a tunnel under the skin was anastomosed to the brachial artery using an end-to-side anastomosis technique. After the procedure, a closed vacuum drain was placed in the lodge and subcutaneous and skin was closed with appropriate sutures.

In both surgical techniques, arteriotomy for anastomosis was performed at a level of $<5 \mathrm{~mm}$ as possible, thus minimizing distal extremity ischemia.

\section{Results}

A total of 117 patients underwent proximal AVF in six years. There were 65 females and 52 males in our study. The patients showed a homogeneous distribution in terms of gender $(\mathrm{p}>0.05)$. The mean age was $60.6 \pm 13.6$ years. Operative and demographic data of the patients are summarized in Table 1 . 


\section{Cureus}

\begin{tabular}{|c|c|c|}
\hline & Mean (SD), n (\%) & $p$ value \\
\hline Age (year) & $60.6 \pm 13.6$ & \\
\hline \multicolumn{3}{|l|}{ Gender $^{\mathrm{a}}$} \\
\hline Male & 52 (44.4) & 0.229 \\
\hline Female & $65(55.6)$ & \\
\hline \multicolumn{3}{|l|}{ Target arm ${ }^{\mathrm{a}}$} \\
\hline Left forearm & $100(85.5)$ & $<0.0001$ \\
\hline Right forearm & 17 (14.5) & \\
\hline \multicolumn{3}{|l|}{ AVF position ${ }^{\mathrm{a}}$} \\
\hline Left BCAVF & 73 (62.4) & \\
\hline Right BCAVF & $14(12)$ & $<0.0001$ \\
\hline Left BVTAVF & $27(23.1)$ & \\
\hline Righ BVTAVF & $3(2.5)$ & \\
\hline \multicolumn{3}{|l|}{ Concomitant diseases } \\
\hline Diabetes mellitus & 47 (40.2) & \\
\hline Hypertension & 74 (63.2) & \\
\hline Coronary artery disease & $26(22.2)$ & \\
\hline Atherosclerosis & $37(31.6)$ & \\
\hline Hyperlipidemia & $29(24.8)$ & \\
\hline Morbid obesity (BMI $\geq 40$ ) & 24 (20.5) & \\
\hline Peripheral arterial disease & 39 (33.3) & \\
\hline \multicolumn{3}{|l|}{ First cannulation time (day) ${ }^{b}$} \\
\hline BCAVF & $41.3 \pm 9.7$ & 0.050 \\
\hline BVTAVF & $37.9 \pm 9$ & \\
\hline
\end{tabular}

\section{TABLE 1: Operative and demographic features}

BCAVF: brachiocephalic arteriovenous fistula; BVTAVF: basilic vein transposition arteriovenous fistula; BMI: body mass index

${ }^{\mathrm{a} A}$ chi-square homogeneity test was used.

${ }^{\mathrm{b}} \mathrm{An}$ independent two-sample t-test was used.

BCAVF was opened in 87 patients and BVTAVF was opened in 30 patients. There was no homogeneous distribution in terms of the target arm ( $\mathrm{p}<0.001)$. It was determined that the left forearm $(85.5 \%)$ was significantly more preferred than right forearm $(14.5 \%)(p<0.001)$. There was no homogeneous distribution in terms of AVF position ( $p<0.001)$. Left BCAVF $(62.4 \%$ ) and left BVTAVF $(23.10 \%)$ were seen significantly higher than other graft positions ( $p<0.001$ ). The time to start dialysis was determined as $41.3 \pm 9.7$ days in BCAVF and 37.7 \pm 9.2 days in BVTAVF ( $p=0.05$ ). It was found that 109 (93.2\%) patients had previously opened multiple AVF from the distal regions and thrombosed over time. In the other 8 (6.8\%) patients, it was found that the distal vascular bed was insufficient and the proximal AVF was opened because the vascular structures were extremely thin. The most common causes of renal failure were hypertension and diabetes mellitus (Table 2). 


\section{Cureus}

Cause

Primary glomerulonephritis

Diabetic nephropathy

Polycystic renal disease

Obstructive stone disease

Hypertension

Pyelonephritis

Autoimmune disease

Congenital renal disease

Renovascular disease

Various

Unknown n (\%)

3 (2.6)

23 (19.7)

5 (4.3)

$2(1.7)$

39 (33.3)

3 (2.6)

$2(1.7)$

4 (3.4)

$12(10.2)$

$11(9.4)$

$13(11.1)$

TABLE 2: Cause of end-stage renal disease

The most common complications in the first three months were bleeding and hematoma in both BCAVF (12 patients) and BVTAVF (4 patients). It was found that all of these patients recovered without intervention requirement. During the follow-up period, the total infection rate was approximately $5 \%$. The fistula thrombosis developed in 21 patients out of 117 patients, with 15 patients with BCAVF and 6 patients with BVTAVF. Hand ischemia due to steal syndrome developed in six patients (6.9\%) with BCAVF and two patients (6.7\%) with BVTAVF (Table 3). 


\section{Cureus}

\begin{tabular}{|c|c|c|c|c|c|}
\hline Months & Complications & BCAVF, $n=87$ & BVTAVF, $\mathrm{n}=\mathbf{3 0}$ & Total, n (\%) & $p$ value \\
\hline \multirow{5}{*}{3} & Thrombosis & 3 & 1 & $4(3.4)$ & 0.976 \\
\hline & Bleeding/hematoma & 12 & 4 & $16(13.7)$ & 0.950 \\
\hline & Hand ischemia/steal & 2 & 0 & $2(1.7)$ & 0.402 \\
\hline & Infection & 4 & 2 & $6(5)$ & 0.658 \\
\hline & Venous hypertension & 0 & 1 & $1(0.9)$ & 0.087 \\
\hline \multirow{3}{*}{6} & Thrombosis & 3 & 1 & $4(3.4)$ & 0.976 \\
\hline & Pseudoaneurysm & 2 & 1 & $3(2.7)$ & 0.757 \\
\hline & Hand ischemia/steal & 3 & 0 & $3(2.7)$ & 0.303 \\
\hline \multirow{5}{*}{9} & Thrombosis & 1 & 1 & $2(1.7)$ & 0.426 \\
\hline & Pseudoaneurysm & 2 & 0 & $2(1.7)$ & 0.402 \\
\hline & High output heart failure & 1 & 0 & $1(0.9)$ & 0.555 \\
\hline & Venous hypertension & 5 & 3 & $8(6.8)$ & 0.426 \\
\hline & Venous aneurysm & 1 & 2 & $3(2.7)$ & 0.099 \\
\hline \multirow{4}{*}{12} & Thrombosis & 4 & 1 & $5(4.3)$ & 0.792 \\
\hline & Hand ischemia/steal & 1 & 2 & $3(2.7)$ & 0.099 \\
\hline & Venous hypertension & 1 & 1 & $2(1.7)$ & 0.426 \\
\hline & Venous aneurysm & 7 & 2 & $9(7.7)$ & 0.807 \\
\hline \multirow{3}{*}{24} & Thrombosis & 4 & 2 & $6(5.1)$ & 0.658 \\
\hline & Pseudoaneurysm & 0 & 2 & $2(1.7)$ & 0.015 \\
\hline & Venous aneurysm & 2 & 2 & $4(3.4)$ & 0.256 \\
\hline
\end{tabular}

TABLE 3: Complications at follow-up months

It was observed that banding was applied to three patients with ischemia, and two patients were relieved with medical treatment (Figure 3). 


\section{Cureus}

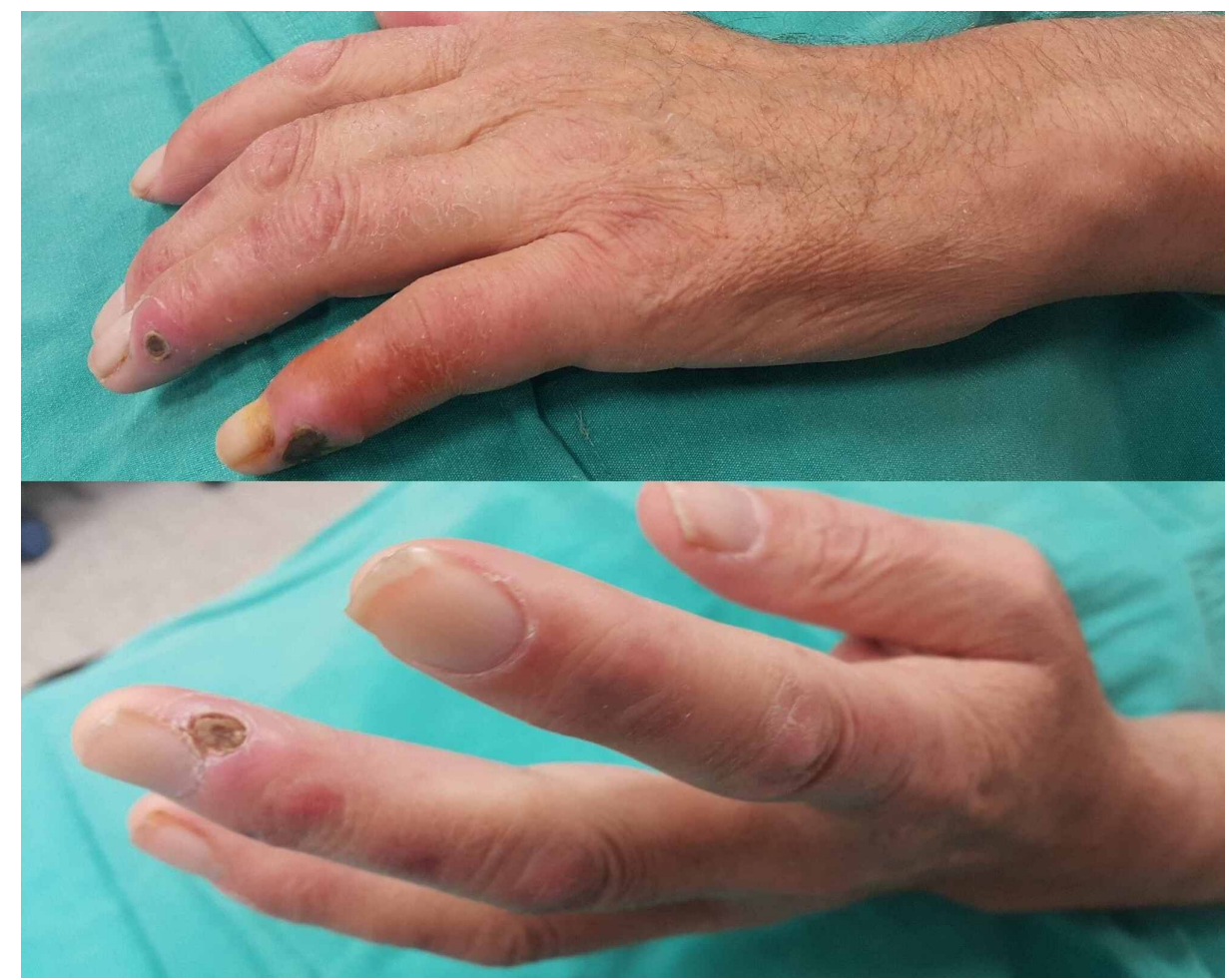

\section{FIGURE 3: Hand ischemia}

It was found that the fistula of three patients developed steal syndrome and they had severe pain, edema and ischemic symptoms (Figure 4).

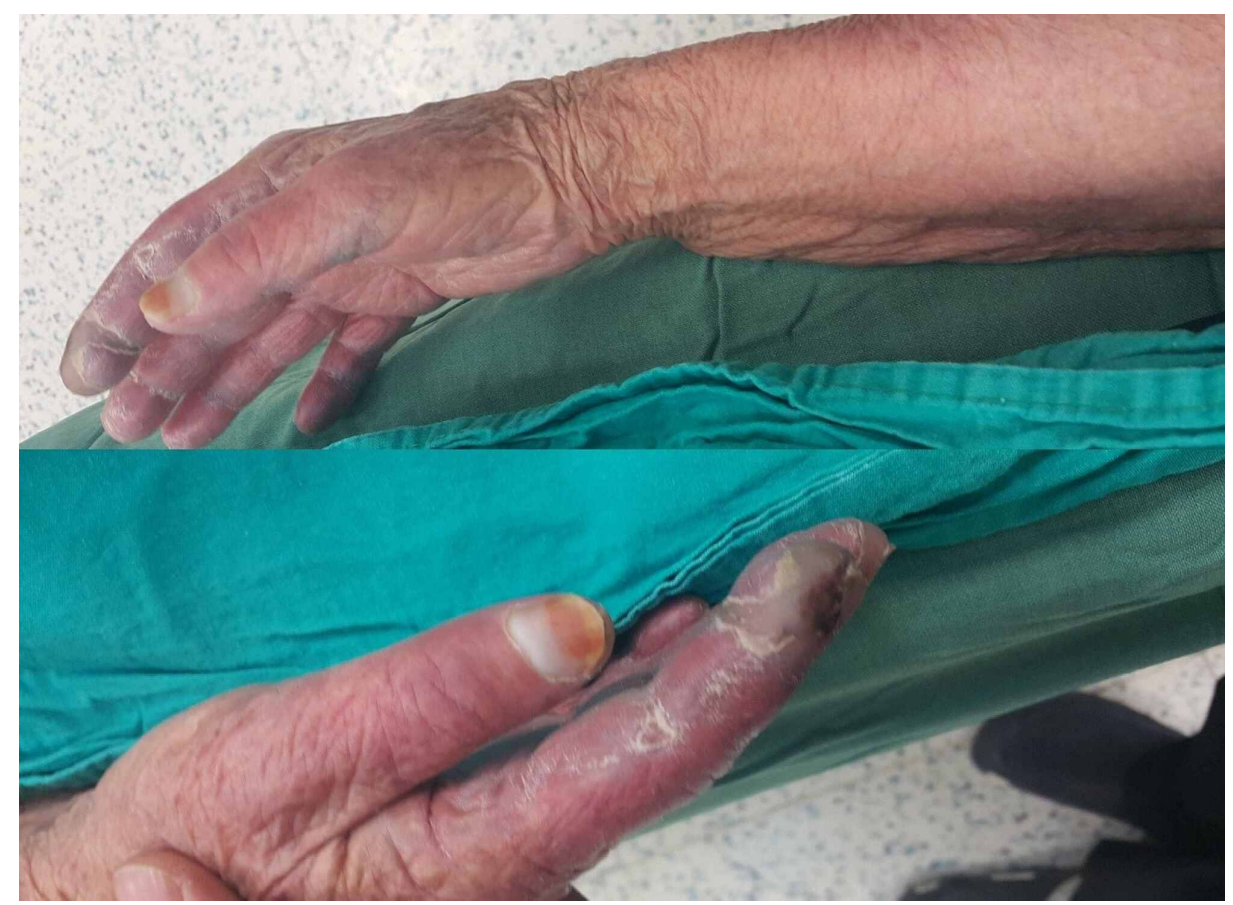

FIGURE 4: Steal syndrome

Venous aneurysm developed in 16 patients during the follow-up period (Figure 5). 


\section{Cureus}

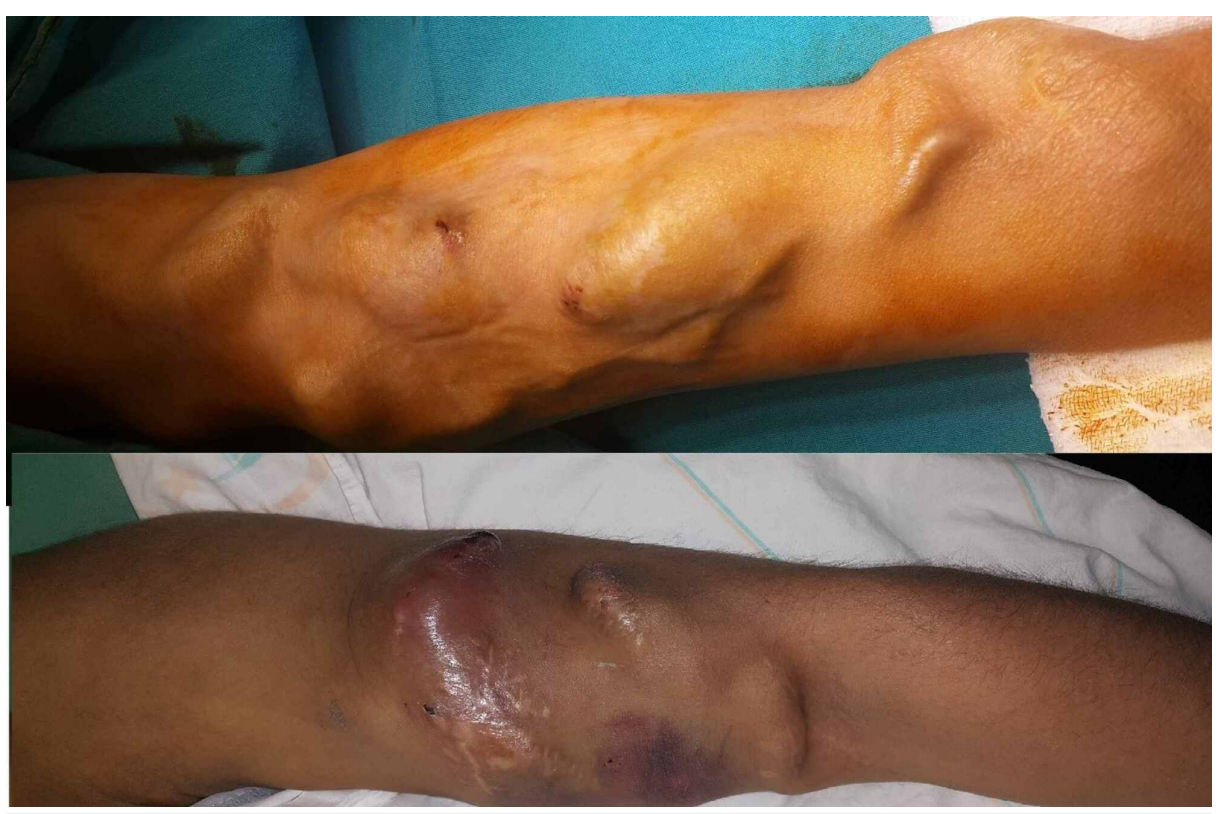

FIGURE 5: Venous aneurism

In the echocardiography performed on a patient who came to the polyclinic with shortness of breath, heart failure due to high output was found in the ninth month. As a matter of fact, the fistula flow rate in the color Doppler ultrasonography performed on this patient was $2300 \mathrm{~mL} / \mathrm{min}$. The fistula of this patient had to be closed. There was no significant difference in the complications at follow-up months except for pseudoaneurysm ( $p>0.05)$. Pseudoaneurysm was seen more significantly in BVTAVF $(\mathrm{p}<0.05)$ (Table 3). The percentages of primary patency rates at $3,6,9,12$, and 24 months were $96.6 \%, 93.1 \%, 92 \%, 87.4 \%$, and $82.8 \%$ in BCAVF patients, and $96.7 \%, 93.3 \%, 90 \%, 86.7 \%$, and $80 \%$ in BVTAVF patients, respectively (Figure 6).

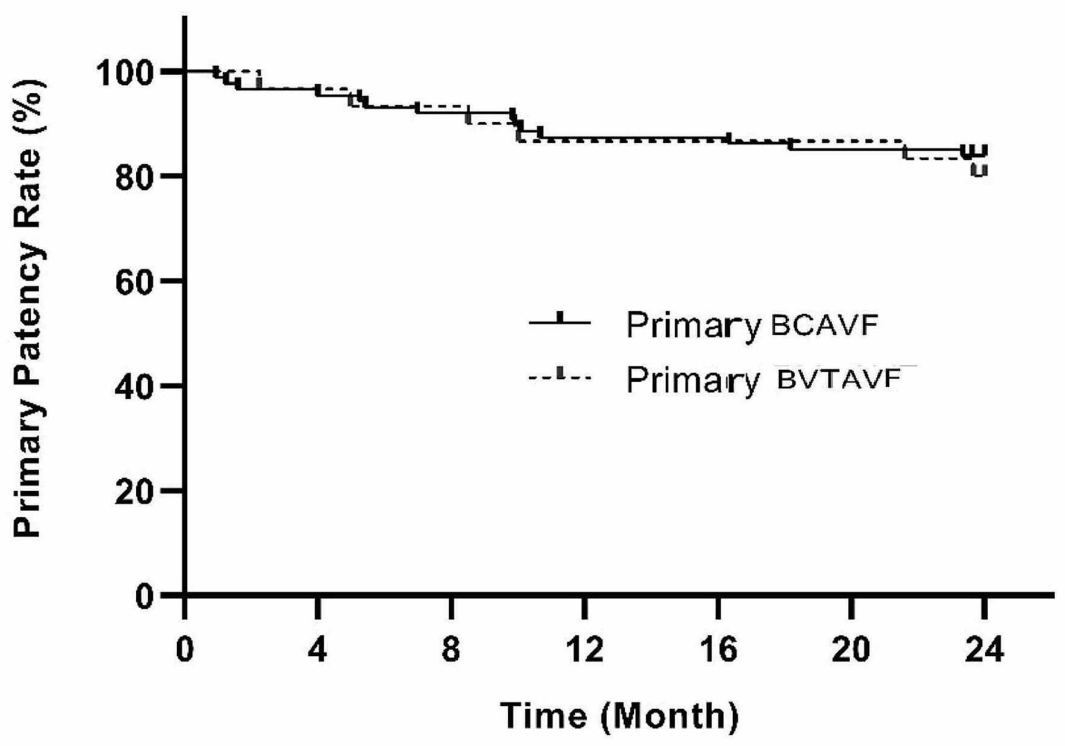

\section{FIGURE 6: Primary patency rate}

BCAVF: brachiocephalic arteriovenous fistula; BVTAVF: basilic vein transposition arteriovenous fistula

The percentages of secondary patency rates at 6,12 , and 24 months were $100 \%, 93.3 \%$, and $86.7 \%$ in BCAVF patients, and $100 \%, 100 \%$, and $87.7 \%$ in BVTAVF patients, respectively (Figure 7 ). 


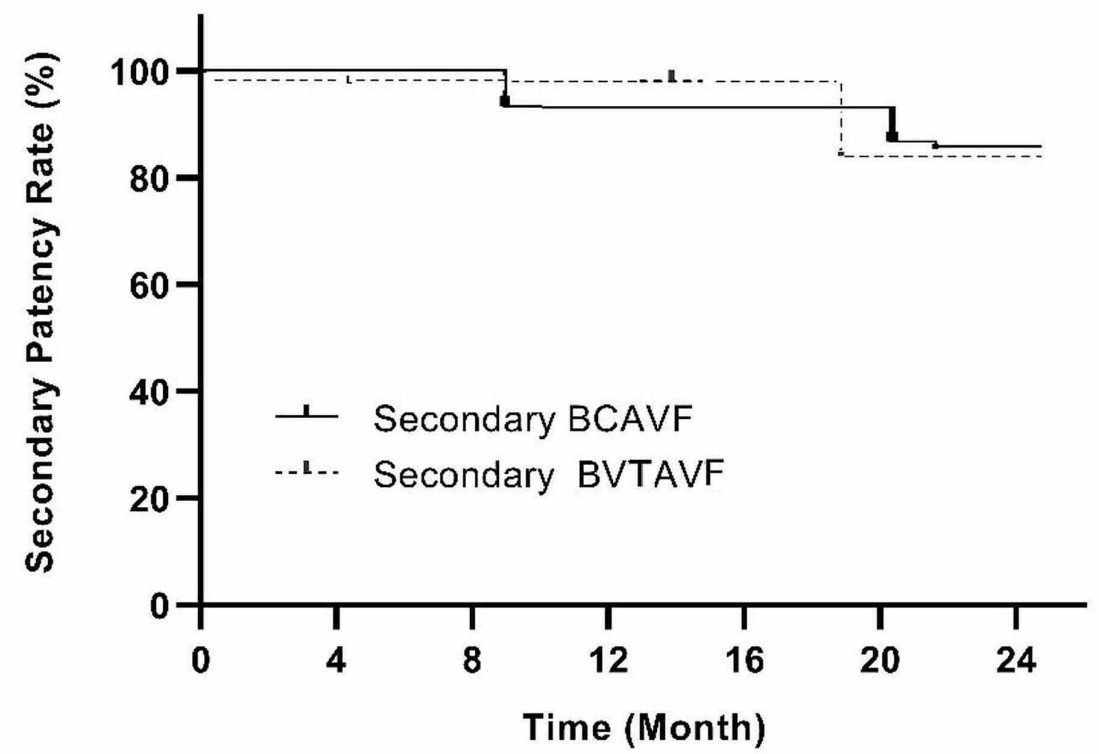

FIGURE 7: Secondary patency rate

BCAVF: brachiocephalic arteriovenous fistula; BVTAVF: basilic vein transposition arteriovenous fistula

\section{Discussion}

Hemodialysis patients need more than one vascular access procedure throughout their lives. Autogenous AVFs are the most preferred vascular access for this purpose [7]. They are preferred more frequently than nonautogenous grafts and central catheters due to their high long-term patency rates and lower risk of thrombosis and infection [8,9]. According to the National Kidney Foundation - Dialysis Outcomes Quality Initiative (NKF-DOQI) and the Society for Vascular Surgery's 2008 Clinical Practice Guidelines, the order of preference is distal radiocephalic, elbow BCAVF, and BVTAVF [10,11]. In 109 of 117 patients in our study, it was observed that proximal BCAVF and BVTAVF were switched over to after distal AVFs were opened and thrombosed over time. In the other eight patients in the study, proximal AVF was preferred because the distal vascular bed was not good. In a study reported by Başer et al., early and late success rates of AVF in the proximal were $90.3 \%$ and $84.9 \%$, respectively, while they were $76.9 \%$ and $69.2 \%$ in the distal. In this study, 31 (23.5\%) complications were observed in proximal fistulas. Early thrombosis was found in 18 (13.6\%), late thrombosis in 8 (6.1\%), bleeding in 2 (1.5\%), infection in $2(1.5 \%)$ and pseudoaneurysm in $1(0.8 \%)$ [12]. In another study by Wen et al., primary patency rates were reported to be $83.3 \%$ and $75 \%$, respectively, during the three- and six-month follow-up periods for BCAVFs opened proximally. In this study, the early thrombosis rate was $18.8 \%$ [13]. In a meta-analysis by Sheta et al., primary patency rates for BVTAVF were found to be approximately $85 \%$ [14]. In the literature review, the primary patency rate of primary fistulas was found to be $75 \%$ to $90.3 \%$ [12-14]. In our study, the percentages of primary patency rates at $3,6,9,12$, and 24 months were $96.6 \%, 93.1 \%, 92 \%, 87.4 \%$, and $82.8 \%$ in BCAVF patients, and $96.7 \%, 93.3 \%, 90 \%, 86.7 \%$, and $80 \%$ in BVTAVF patients, respectively. The percentages of secondary patency rates at 6,12 , and 24 months were $100 \%$, $93.3 \%$, and $86.7 \%$ in BCAVF patients, and $100 \%$, 100\%, and $87.7 \%$ in BVTAVF patients, respectively. These rates are higher than those found in the literature. We attribute that all fistulas in the study were performed by a single surgical team. To our knowledge, our health center is the only center performing fistula surgery in the region and our surgical team is the only team with experience in this field, increasing the success of fistula surgery. Early thrombosis (within the first three months) was observed in $3.4 \%$ of our patients, and late thrombosis (between three months and two years) was observed in $14.6 \%$ of our patients. In the literature review, high complications in BVTAVF are mentioned and this is connected to long incisions used for basilic vein exploration. Complication rates are between $47 \%$ and $71 \%$ [15]. In our study, the general complication rates in the first three months were determined as 24\% in BCAVF and 26\% in BVTAVF. It was observed that the most common complications were bleeding and hematoma. None of these patients required intervention. The most important and only technical difficulty in BVTAVF is to perform surgery for obese patients and access fistula for hemodialysis in patients with thick subcutaneous adipose tissue [16]. Edema or venous hypertension is another disadvantage of proximal fistulas. This is mostly due to extensive incisions and cutting of dense collateral veins or thrombosis of these veins over time. This may cause edema by reduction in venous return in the extremity [17]. Edema makes fistula access difficult during dialysis. It can also cause subcutaneous bleeding and hematomas due to multiple attempts. In a study by Veeramani et al., the incidence of edema was found to be $14.2 \%$ [18]. In our study, arm edema 
(venous hypertension) occurred in 11 patients out of 117 patients during the follow-up period. There were 6 (5\%) patients in the BCAVF and 5 (16.7\%) patients in BVTAVF group. No additional intervention was made to any of these patients. It was followed by effective elevation. Another complication in fistula surgery is arterial steal syndrome. This is especially seen in patients with diabetic and atherosclerotic vascular disease and proximal fistulas $[19,20]$. The rate of steal syndrome requiring intervention in the literature is approximately $2.9 \%$ to $3.9 \%$. In the treatment of this condition, which has the risk of loss of extremity, it requires banding or complete ligation of the fistula [21]. In our series, this rate was found to be $6.9 \%$ in BCAVF patients and $6.7 \%$ in BVTAVF patients. Because three of these patients had severe pain and limb ischemia, the fistula had to be closed. It was found that two of the other five patients were relieved by medical treatment, and three of them had their fistula narrowed by taping method. These taped patients continued to use their fistulas without any problems. Two-year secondary patency rates were $>85 \%$. Aneurysms, which are one of the late fistula complications in dialysis patients, are generally true aneurysms and their etiology is not clear. However, repeated needles or connective tissue disorder in the same area is to be blamed. Their incidence varies between $5 \%$ and 60\% [22-25]. In our study, after the sixth month, true venous aneurysms were detected at $11.5 \%$ in BCAVF patients and $20 \%$ in BVTAVF patients. These rates were similar to the literature. Our pseudoaneurysm rate was $6 \%$ with seven patients at the two-year follow-up. In such aneurysms, it occurs with the weakening of the vascular wall as a result of repeated punctures performed in the same area during dialysis [26]. High-output heart failure is a rare but serious complication described in the literature. There is high evidence that a fistula with a high output, such as worsening or inducing left ventricular hypertrophy, can contribute to the high cardiovascular risk factor present in patients with renal insufficiency $[27,28]$.

This complication, which was observed in $0.9 \%$ with only one patient in our study, was treated with fistula closure. After the fistula is formed, a maturation period is expected for fistula cannulation for an average of three to six months. Meanwhile, the patient starts dialysis with a central venous catheter. This brings additional complications [29]. This period was 41.3 \pm 9.7 days in BCAVF patients and 37.9 \pm 9.2 days in BVTAVF patients in our study group. This seemed to be the most important advantage of proximal fistulas.

\section{Conclusions}

Proximal arteriovenous fistulas appear to be advantageous with high primary patency rates, secondary patency rates and early dialysis times. We believe that aneurysm formation and steal syndrome, which are relatively high in proximal compared to distal arteriovenous fistulas, can be prevented by appropriate surgical techniques and punctures in different regions during dialysis. Proximal arteriovenous fistulas are an appropriate vascular access route in patients whose distal vascular bed is depleted or unsuitable.

\section{Additional Information}

\section{Disclosures}

Human subjects: Consent was obtained by all participants in this study. Institutional Review Board, Adryaman University Medical Faculty issued approval 2020/1-5. This study was approved by the Institutional Review Board of the Adıyaman University Medical Faculty, where the study was conducted (approval no. 2020/1-5). Animal subjects: All authors have confirmed that this study did not involve animal subjects or tissue. Conflicts of interest: In compliance with the ICMJE uniform disclosure form, all authors declare the following: Payment/services info: All authors have declared that no financial support was received from any organization for the submitted work. Financial relationships: All authors have declared that they have no financial relationships at present or within the previous three years with any organizations that might have an interest in the submitted work. Other relationships: All authors have declared that there are no other relationships or activities that could appear to have influenced the submitted work.

\section{References}

1. Mehra K, Manikandan R, Dorairajan LN, Sreenivasan Kodakkattil S, Kalra S, Kumar R, Murali P: Outcomes of transposition of brachiobasilic arteriovenous fistula in two-stage technique: a single-centre experience with literature review. Cureus. 2020, 12:e9949. 10.7759/cureus.9949

2. NKF KDOQI guidelines. Clinical practice guidelines and clinical practice recommendations - 2006 updates . (2006). Accessed: February 17, 2020: http://kidneyfoundation.cachefly.net/professionals/KDOQI/guideline_upHD_PD_VA/index.htm.

3. Chipde SS, Agrawal S, Kalathia J, Mishra U, Agrawal R: Basilic vein transposition: a viable alternative for multiple failed arteriovenous fistulas - a single center experience. Saudi J Kidney Dis Transpl. 2017, 28:336340. 10.4103/1319-2442.202781

4. Wang S, Wang MS, Jennings WC: Basilic elevation transposition may improve the clinical outcomes for superficialization of basilic arteriovenous fistula veins. J Vascular Surg. 2007, 65:1104-1112. 10.1016/j.jvs.2016.10.081

5. Lin YC, Huang YY, Lin MY, Chiu YW, Lim LM, Hsieh CC: Long-term outcomes of lateral tunneled transposed brachiobasilic arteriovenous fistulas in elderly hemodialysis patient. J Vasc Access. 2019, 20:557-562. $10.1177 / 1129729818820184$

6. Kakkos SK, Kouri AK, Tsolakis IA, Haddad GK, Lampropoulos GC, Karnabatidis D: Surgical and endovascular revision of brachio-basilic vein fistula. J Vasc Access. 2016, 1:6-11.

7. Santoro D, Benedetto F, Mondello P, et al.: Vascular access for hemodialysis: current perspectives. Int J 
Nephrol Renovasc Dis. 2014, 7:281-294. 10.2147/IJNRD.S46643

8. Hu D, Li C, Sun L, et al.: A modified nontransposed brachiobasilic arteriovenous fistula versus brachiocephalic arteriovenous fistula for maintenance hemodialysis access. J Vasc Surg. 2016, 64:1059-1065. 10.1016/j.jvs.2016.03.450

9. Viecelli AK, O'Lone E, Sautenet B, et al.: Vascular access outcomes reported in maintenance hemodialysis trials: a systematic review. Am J Kidney Dis. 2018, 71:382-391.

10. Sidawy AN, Spergel LM, Besarab A, et al.: The Society for Vascular Surgery: clinical practice guidelines for the surgical placement and maintenance of arteriovenous hemodialysis access. J Vasc Surg. 2008, 48:S2-S25. 10.1016/j.jvs.2008.08.042

11. Slinin Y, Greer N, Ishani A, MacDonald R, Olson C, Rutks I, Wilt TJ: Timing of dialysis initiation, duration and frequency of hemodialysis sessions, and membrane flux: a systematic review for a KDOQI clinical practice guideline. Am J Kidney Dis. 2015, 66:823-836. 10.1053/j.ajkd.2014.11.031

12. Başer M, Sayarlıoğlu H, Doğan E, Erkoç R, Çiftçi A, Kotan MÇ: Comparison of proximal distal success rate in A-V fistulas settled for hemodialysis. Van Med J. 2006, 13:42-45.

13. Wen M, Li Z, Li J, Zhou W, Liu Y, Liu H, Chen G: Risk factors for primary arteriovenous fistula dysfunction in hemodialysis patients: a retrospective survival analysis in multiple medical centers. Blood Purif. 2019, 48:276-282. 10.1159/000500045

14. Sheta M, Hakmei J, London M, Wooster M, Aruny J, Ross J, Illig KA: One- versus two-stage transposed brachiobasilic arteriovenous fistulae: a review of the current state of the art. J Vasc Access. 2020, 21:281286. 10.1177/1129729819862694

15. Taghizadeh A, Dasgupta P, Khan MS, Taylor J, Koffman G: Long-term outcomes of brachiobasilic transposition fistula for haemodialysis. Eur J Vasc Endovasc Surg. 2003, 26:670-672. 10.1016/j.ejvs.2003.09.002

16. İşcan Ş, Çakır H: Basilic vein transposition should be the first option. Anatol J Cardiol. 2015, 15:166-167. 10.5152/akd.2015.5997

17. Gibyeli Genek D, Tuncer Altay C, Unek T, Sifil A, Seçil M, Camsari T: Can primary failure of arteriovenous fistulas be anticipated?. Hemodial Int. 2015, 19:296-305. 10.1111/hdi.12206

18. Veeramani M, Vyas J, Sabnis R, Desai M: Small incision basilic vein transposition technique: a good alternative to standard method. Indian J Urol. 2010, 26:145-147. 10.4103/0970-1591.60466

19. Littler P, Cullen N, Gould D, Bakran A, Powell S: AngioJet thrombectomy for occluded dialysis fistulae: outcome data. Cardiovasc Intervent Radiol. 2009, 32:265-270. 10.1007/s00270-008-9478-2

20. Dixon BS, Novak L, Fangman J: Hemodialysis vascular access survival: upper-arm native arteriovenous fistula. Am J Kidney Dis. 2002, 39:92-101. 10.1053/ajkd.2002.29886

21. Wixon CL, Hughes JD, Mills JL: Understanding strategies for the treatment of ischemic steal syndrome after hemodialysis access. J Am Coll Surg. 2000, 191:301-310. 10.1016/s1072-7515(00)00335-5

22. Al-Thani H, El-Menyar A, Al-Thani N, et al.: Characteristics, management, and outcomes of surgically treated arteriovenous fistula aneurysm in patients on regular hemodialysis. Ann Vasc Surg. 2017, 41:46-55. 10.1016/j.avsg.2016.08.046

23. Valenti D, Mistry H, Stephenson M: A novel classification system for autogenous arteriovenous fistula aneurysms in renal access patients. Vasc Endovascular Surg. 2014, 48:491-496. 10.1177/1538574414561229

24. Rajput A, Rajan DK, Simons ME, et al.: Venous aneurysms in autogenous hemodialysis fistulas: is there an association with venous outflow stenosis?. J Vasc Access. 2013, 14:126-130. 10.5301/jva.5000111

25. Field MA, McGrogan DG, Tullet K, Inston NG: Arteriovenous fistula aneurysms in patients with Alport's . J Vasc Access. 2013, 14:397-399. 10.5301/jva.5000167

26. Murea M, Geary RL, Davis RP, Moossavi S: Vascular access for hemodialysis: a perpetual challenge . Semin Dial. 2019, 32:527-534. 10.1111/sdi.12828

27. Baktiroglu S, Yanar F, Ozturk A: Brachiocephalic and basilic fistula. J Vasc Access. 2015, 16:S29-S33. 10.5301/jva.5000377

28. Faull R, Rao N, Worthley M: Do arteriovenous fistulas increase cardiac risk? . Semin Dial. 2018, 31:357-361. 10.1111/sdi.12687

29. Saran R, Li Y, Robinson B, et al.: US Renal Data System 2015 annual data report: epidemiology of kidney disease in the United States. Am J Kidney Dis. 2016, 67:S1-S434. 10.1053/j.ajkd.2015.12.014 